\title{
A representação dos diacríticos em ortografias seiscentistas
}

\author{
Helena de Oliveira Belleza Negro \\ Universidade de São Paulo (USP), São Paulo, São Paulo, Brasil \\ helena.oliveira@usp.br
}

DOI: http://dx.doi.org/10.21165/el.v46i2.1620

\begin{abstract}
Resumo
O presente trabalho analisará os usos dos diacríticos em duas ortografias do século XVII: $A$ Ortografia da Lingua Portugueza, de João Franco Barreto e a Orthographia ou modo para escrever certo na língua portugueza, de Alvaro Ferreira de Vera. Com base no contexto social e político dos séculos XVI e XVII, buscamos nas obras indícios que validem as abordagens presentes nas ortografias. O seu objetivo é contribuir para os estudos de filologia, linguística histórica e história social.
\end{abstract}

Palavras-chave: filologia; paleografia; historiografia linguística; história social.

\section{The representation of the diacritics in seventeenth century spellings}

\begin{abstract}
The present work will analyze the uses of diacritics in two spellings of the seventeenth century: the A Ortografia da Lingua Portugueza by João Franco Barreto and Orthographia ou modo para escrever certo na língua portugueza by Alvaro Ferreira de Vera. Based on the social and political context of the sixteenth and seventeenth centuries, we sought in the works indications that validate the approaches in the spellings. The objective is to contribute with the studies of philology, historical linguistics and social history.
\end{abstract}

Keywords: philology; paleography; linguistic historiography; social history.

\section{Introdução}

O presente artigo apresentará as ocorrências histórico-sociais, bem como seus reflexos na escrita no decorrer do século XVII e, principalmente, o uso dos sinais diacríticos. Para tanto, buscaremos em ortógrafos seiscentistas parâmetros que possibilitem levantarmos hipóteses acerca desse emprego.

O século XVII foi palco de mudanças sociais que levaram à transformação da literatura e da arte, pois Portugal ainda estava sob influência do humanismo e a busca pela conciliação entre o homem e a religião impulsionavam a economia, colocando em conflito as crenças humanas e o poder do clero. A reforma e a contrarreforma trariam reflexos a Portugal, que, diferentemente dos demais países europeus, mantinha-se fiel a Roma, fazendo com que a identidade religiosa portuguesa sobrepujasse a identidade do reino português.

"No plano interno, o primado da catolicidade sobre a identidade reinícola conduzia à ideia de que a legitimidade do reino estaria dependente de sua fidelidade à Igreja e a identidade dos súbditos à sua adesão à fé do reino e dos seus maiores" (HESPANHA, 1993, p. 21). Essa fidelidade proporcionaria o sucesso às campanhas de evangelização dos povos nativos do Novo Mundo, promovendo a disseminação da 
religião cristã e da língua portuguesa. Sua disseminação foi realizada por meio de gramáticas bilíngues, elaboradas pelos jesuítas, transformadoras da cultura local e disseminadoras do idioma do colonizador.

Atrelada à expansão portuguesa, apresenta-se a questão da língua, vivenciada fortemente em Portugal sob o comando de Filipe II, rei da Espanha, de 1580 até o ano de 1640, pois os portugueses passariam a buscar uma identidade que os qualificassem como unidade, apartados do reino espanhol.

No entanto, a glória das descobertas não sobrepujava a inconstância social diante do julgo de um rei espanhol. A crise no governo português apresentaria seus reflexos nas produções literárias da época e, inserido nesse cenário, o Barroco foi o movimento literário que perdurou no período de 1580 a 1756 . Na contextualização de Moises (1980, p. 155), "constitui-se numa tentativa de fusão harmônica entre as duas linhas de força que orientavam a cultura renascentista (a medieval e a clássica, respectivamente teocêntrica e antropocêntrica)". Nesse contexto, encontramos obras como a Lírica de Camões, que no maneirismo apresentava a transição entre o renascimento e o barroco, e os Sermões de Anchieta que refletem os sentimentos e as ações da sociedade portuguesa no início do século XVII.

No Brasil, as expressões do Barroco foram apresentadas na arte e nas construções. São famosas as igrejas em Minas Gerais, assim como as esculturas de Aleijadinho que representam o movimento no século XVII. A conversão de novas almas ao cristianismo trazia mais força à Igreja que, desde meados do século $\mathrm{XV}$, perdia devotos para novas instituições fundadas em resposta aos interesses sócio-políticos da época, como Igreja Luterana, fundada por Martinho Lutero, na Alemanha, ou a Anglicana, fundada por Henrique VIII.

E foi nesse contexto que alguns estudiosos se debruçaram sobre a escrita da língua portuguesa, elaborando obras que ratificassem e solidificassem a ortografia nacional. Com ênfase nessas abordagens, optamos pela análise da Orthographia ou modo para escrever certo na língua portugueza (1631), de Alvaro Ferreira de Vera, e de A Ortografia da Lingua Portugueza (1671), de João Franco Barreto.

Essas análises terão como base a edição semidiplomática de processos criminais manuscritos do século XVII ao século XX e nos apoiaremos nessa documentação para a realização dos comparativos entre os usos praticados pelos escribas e as propostas apresentadas nas gramáticas e ortografias da época.

\section{A Orthographia ou modo para escrever certo na língua portugueza (1631)}

Álvaro Ferreira de Vera nasceu em Lisboa e era escrivão da Torre do Tombo. De origem ilustre, estudou em colégios jesuítas e foi grande pesquisador, conhecido em sua época pelos estudos genealógicos em Portugal e posteriormente em Madri.

Centralizamos nossas atenções na análise de sua ortografia, que é composta por 34 partes. Remete aos preceitos abordados por Oliveira (1536) ao definir a pronunciação e suas vozes e ao remeter à diferenciação entre a escrita e a fala. Enfatiza, ainda, que é necessário saber o correto uso das letras destinadas a cada palavra e o seu significado. 
No capítulo dois, em que inicia a transcrição das letras do alfabeto, faz referência ao alfabeto hebraico, caldeu, sírio, fenício, grego e, finalmente, ao latino, esclarecendo ainda que o povo fazia uso diferente dos sacerdotes, ou seja, o uso popular das letras era diferente do uso imperial e clerical. Com isso, remete à importância da unidade da escrita, função central da ortografia, que tem como motivação a uniformização linguística.

É perceptível a preocupação de Vera com a pronúncia das 23 letras anunciadas pelo alfabeto latino e que serão adotadas na língua portuguesa, pois as consoantes aspiradas $<\mathrm{ph}>,<\mathrm{rh}>$ e $<$ th $>$ teriam som diverso da escrita. O cuidado não confere a realidade dos sons conhecidos na língua e, seguindo a periodização proposta por Coutinho (2005, p. 75), as premissas adotadas por estes ortógrafos, desde meados do século XVI, representam o período pseudoetimológico, pois "respeitam, tanto quanto possível, as letras originárias da palavra, embora nenhum valor fonético representem".

Entendimento semelhante havia apresentado por Duarte Nunes do Leão (1576) em referência ao uso do $<\mathrm{ph}>\mathrm{e}<\mathrm{th}>$, no capítulo Da diffininição da Orthographia, \& da Voz na Orthographia. Isso ocorreu devido à necessidade de buscar, na raiz latina, o sustentáculo de suas origens, apoiando-se em uma falsa morfologia para estabelecer uma escrita etimológica, mas que em nada referenciava o latim.

Quanto ao uso dos diacríticos, Vera dedica-lhes um capítulo: Dos acentos, \& viraccentos, que usão os Gregos, \& Latinos. \& quando os devemos usar na escritura, em que faz referência explícita aos diacríticos, apresentando-os: "dos tres acentos chamado agudo, grauè, circunflexo usamos somente de dous: \& outro sido chamado Apostropho: como se verá neste trattado" (VERA, 1631, p. 5).

Define "acento" como o "tom de cada syllaba" e nomeia-os com a representação de diferentes sinais gráficos, fazendo referência aos "Latinos". Esclarece, informando que os portugueses usam apenas o agudo e o circunflexo e, em seguida, apresenta com exemplos a aplicação dos sinais, relacionando seus usos à tonicidade aplicada nas palavras com semelhança lexical. Além disso, atrela o uso do diacrítico à tonicidade e à forma como é aplicado nas diferentes ocasiões, realizado em palavras como <amára>, $<$ leéra $>$ e $<$ ouvíra $>$, no pretérito e $<$ amarâ $>$, $<$ leerâ $>$ e $<$ ouvirâ $>$, no futuro do presente.

Accento he tom de cada syllaba. Os Latinos usavão de três, a saber agudo, grave, \& circunflexo, que he composto de ambos. Do primeiro, \& terceiro usamos os Portuguêses nas syllabas qye pronunciadas altas em dicções, que tem as mesmas letras, differenção na significação de aquella, que teem a pronunciação baixa: como amára, léera, ouvíra, amarâ, ouvirâ, pretérito, ou futuro. (VERA, 1631, p. 41).

Com isso, o lisboeta propõe a diferenciação da tonicidade atrelada à mudança de significado lexical. Esse paralelo é perceptível ao diferenciar "bôlo, trôco, que pronunciamos com tom baixo, que significão jogar, bolar, trocar, a diferença de jogo, bolo, troco, que são nomes, que se escrevem com acento agudo, ou sem elle" (VERA, 1631, p. 42), ou seja, na concepção de Vera, os diacríticos são utilizados não somente para diferenciar a tonicidade, mas também representam a diferença entre os vocábulos.

Assim, demarca uma diferenciação na aplicação do diacrítico. Esse comportamento repetiu-se nos exemplos <amára $>$ e <leéra $>$, em que assinala com 
agudo a penúltima sílaba mais forte, enquanto <amarâ> e <leerâ> marca com circunflexo.

Analisando os parâmetros do ortógrafo para usar os diacríticos, concluímos que se baseou na tendência fonológica de acentuação da penúltima sílaba, ou seja, embasouse na pronunciação para utilizar os diacríticos, com o intuito de transcrever os modos da fala, representando a altura vocálica e a consequente mudança verbal.

Esse é o primeiro caso em que há uma tentativa de delimitação e regramento para utilização dos diacríticos, pois o que se verifica, a partir do século XVIII, é a adoção de um único diacrítico para disseminação da escrita.

Essa interpretação prevalece, quando o autor recomenda que "nunqua escrevamos acento grave pelo agudo, ou circunflexo, porque sômente dele usão os Latinos em advérbios" (VERA, 1631, p. 42). No entanto, no decorrer dos séculos é muito usual encontrar o uso do agudo em substituição ao til, ou ainda, o circunflexo com função nasal ou o circunflexo em lugar do agudo, se compararmos com as funções que estes diacríticos possuem na atualidade. Processos criminais elaborados no século XVII apresentam essas características em $<$ huâ $>,(1695,5 \mathrm{v}, 1.09)$, em que o circunflexo faz a função do til. No século XVIII, encontramos <maó> $(1744,1 \mathrm{v}, 1.28$; 2r, 1s 19 e 30; 2v, ls 06 e 36; 3r, ls 5 e 29; 4r, 1.35 e 5r, ls 14 e 36), em que o agudo faz a função do til e no século XIX <jâ> (1800, 2r, 1. 04), em que o circunflexo faz a função do agudo. Não foi localizado o diacrítico grave em nenhuma ocorrência, nem nos advérbios, mas encontramos o circunflexo com a função que o grave exerceria, conforme proposto pelo autor.

Diante disso, vislumbramos a apresentação de um novo conceito para o uso dos diacríticos, pois aqui ele deixaria de ser o "tom da dicção" como afirmou um século antes Fernão de Oliveira (1536) e seria representado por um sinal gráfico.

Como Duarte Nunes do Leão (1576), Vera também faz referência ao apóstrofo e afirma que "alem destes três acentos usaõ os Gregos d'outro mais, a que chamão Apostropho, tendo entre os mais o mesmo nome: o que na realidade não he, porque sô de nota a vogal, que se tira do fim da dicção, pela figura chamada synalepha" (VERA, 1631, p. 42). A língua portuguesa faz uso desse diacrítico "quãdo se segue outra dicção, que outro si começa em vogal: como d'ouro, est'anno, d'Evora” (p. 42). A descrição da necessidade de utilização do apóstrofo tem uma justificativa fonética, pois $o$ "viraccentos se faz de necessidade no verso, para se evitar ohiato, \& abertura da bocca, que causa acabando hua dicção em vogal \&começa também a seguinte em outro" (p. 42).

Sobre o uso do til, o ortógrafo lisboeta dedica o capítulo XXVI, chamado Sobre a Abbreviação a que chamamos Til, definindo:

Til não he letra, senão hum risco sobre vogal $\mathrm{O}$ qual se escreve nas dicções de muitas letras suprindo com poucas muitas: como se vê nessas palavras, Misericordia Sentença $\&$ nos nomes patronymicos, como Gonçalvez, Fernandez, Rodriguez \& outros taes, em que escusamos com o til de escrever tantas letras como Mtã, deixamos de escrever, isericord \& asi nos mais escrevendo somente Sñça, Frz, Clz, \&c. (VERA, 1631, p. 24). 
Para além da abreviatura, o autor também referencia o uso do diacrítico para supressão das consoantes nasais $<\mathrm{m}>\mathrm{e}<\mathrm{n}>$, como abordado pelos gramáticos e ortógrafos que o antecederam, como Oliveira (1536), Barros (1540), Gândavo (1574) e Leão (1576). O uso das consoantes, como realizado no latim, poderia ser substituído pelo sinal gráfico em palavras com final $<$ am $>$, dando lugar à formação <ão $>$.

Ao final desse capítulo, Vera resume o pensamento que o levou a seguir muitos parâmetros apresentados em sua obra, dentre eles, o uso do til e as constantes referências aos modelos greco-latinos.

[...] que escrevemos assi, como os Latinos, polos não corrompermos, imitando sempre as escrituras dos homẽs doutos, regulandoas, pelo entendimento, \& ouvido, que he a melhor regra, que se poder têr, \& dar nesta matéria (VERA, 1631, p. 25).

Fazendo jus às palavras inseridas no prólogo da Orthographia, o autor remete à sabedoria e à boa escrita dos homens doutos, ou seja, àqueles que conheciam a escrita e sabiam fazê-la bem. Vera tem em mente que sábios são aqueles que conhecem o grego e o latim e que têm a habilidade de apresentar a escrita dos fenômenos da pronunciação.

Apesar da influência da obra de Duarte Nunes do Leão (1576) na escrita da Orthographia de Vera, não podemos deixar de observar que o ortógrafo era escrivão da Torre do Tombo e estudou em colégios jesuítas. Sua formação e a preocupação com o escrever como se lê, é defendida em sua obra:

[...] escrever, como se pronũcia, he com a pena imitar a língua, estampar com letras aquillo, que declaramos com palavras: (não acrescentando, bem diminuindo, pois não he necessário, antes fique sendo mais perfeito o modo de aquelle, que cõ esta arte imita a natureza) \& quanta mais propriedade tiver nos pontos \& acentos, tãta mais ventajem terá. Porque as letras se inventárão para dar noticia em presença das cousas, que se fizeram em ausência: o que naõ poderá fazer escrevendose confuso. (VERA, 1631, p. 2)

Em comparação às duas obras - a de Vera (1631) e Leão (1576) - facilmente identificamos as similaridades entre ambos, principalmente no que se refere à nomeação e identificação dos sinais gráficos que marcam a tonicidade.

\section{A Ortografia da Lingua Portugueza (1671)}

João Franco Barreto nasceu em Lisboa no ano de 1600 e atuou como pároco em Évora e Setúbal. Em 1624, partiu em expedição para o Brasil para expulsar os holandeses da costa brasileira. Estudou direito canônico na universidade de Coimbra e atuou como preceptor. Viajou à França e, retornando a Lisboa, publicou a narração de sua viagem, tomando as ordens eclesiásticas.

Sobre o uso dos diacríticos, o autor dedica o capítulo 52. Assim como Vera (1631), João Barreto também se refere aos diacríticos como acentos, dando ênfase para a pronunciação e às suas particularidades. $\mathrm{O}$ ortógrafo ressalta que o uso do diacrítico para marcar o acento apresenta-se como uma diferenciação em relação aos demais 
idiomas. Entendemos como clara referência à manutenção de um purismo da língua, enaltecendo o idioma pátrio em comparação aos demais ao afirmar que

A matéria prezente he das mays dificeys da ortografia, como sentem todos os que dela escrevem \& assi poucos tẽ acertado: màs he tão importante, que uma das principaes causas, porque a pronunciaçã da língua se faça eterna, \& mays, facilmente se conserve inviolada entre as barbaras nações: saõ os acentos como testimunhan as línguas Hebrea, \& Grega; adonde seus acentos, cõ que se asinalam suas dições nã foram, ainda que soubéssemos pronunciar suas letras, contudo nã soubéramos profirir suas palavras (BARRETO, 1671, p. 202).

Também relaciona o uso do acento ao modo de pronunciação e da "detença de tempo, ẽ que saõ pronunciadas da propriedade do idioma particular ẽ que se fala" (BARRETO, 1671, p. 202). Ao definir os diacríticos agudo, grave e circunflexo como usuais, remete à tonicidade silábica, pois a função do agudo é "levantar mays tõ da silaba onde está o grave tẽ este nome, porque abayxa a silaba é que se situa \& o circunflexo, assim como na figura participa de ambos, ẽ o mesmo tempo: ainda que esta pronunciaçã dizem se nã sabe ẽ nossos tempos, como ella fosse" (BARRETO, 1671, p. 203).

Explica o uso dos acentos e define como aplicá-los, remetendo à tonicidade silábica e ao ritmo, uma vez que os relaciona às pausas em um verso, ou seja, o acento está relacionado ao ritmo e à entonação e, novamente, como Vera, Barreto esboça um regramento para a aplicação dos diacríticos.

Demaneyra que do acento grave usam os Latinos, para distinçã das palavras sómente, \& do agudo, \& circunflexo, na silaba, onde mays se levanta a voz. Destes acentos poys usaremos na maneyra seguinte. Se as palavras forem diversas, \& se escreverem cõ as mesmas letras, como se ve na primeyra \& terceyra pessoa do pretérito plusquam perfeyto, \& na terceyra pessoa do futuro dos verbos amar, ouvir \& c, para mostrarmos essa diversidade, escreveremos as pessoas do pretérito cõ acento agudo na penúltima, como amára, ouvíra, \& a pessoa do futuro cõo mesmo acento é a ultima, como amará ouvirá: màs se a palavra fôr de duas silabas somente, como lêra, fora, se escreverá cõ acento circunflexo, \& se conhecerá bẽ esta diferença na segunda palavra destas duas, porque fora he primeyra \& terceyra do pretérito plusquanperfeyto de verboo sou, \& fóra cõ acento agudo, ẽ o he adverbio (BARRETO, 1671, p. 205).

Baseando-se pelo diacrítico agudo, o ortógrafo direciona a função de tonicidade como ponto principal de marcação de diferenciação entre os tempos verbais. A Orthographia de Vera apresenta esse percurso, centralizando esses diferenciais no emprego do circunflexo.

Para além dos verbos, o uso de diacríticos diferentes também teria como função a distinção lexical, como ocorre com <cor>, de coração, e <côr >, de colorir. Outra função é a representação da quantidade, como ocorre em olho/ólhos, povo/póvos. A esse tópico faz clara referência a Duarte Nunes do Leão (1576) ao diferenciar as palavras pela quantidade e pelo significado e diferentemente de Vera (1631), Barreto traça parâmetros para aplicar os diacríticos. 
No capítulo 53, denominado Dos apóstrofos, o ortógrafo indica quando e como usá-los, realizando breve introdução sobre as origens e sua função, relatando

Ainda que cada vogal de sua natureza tenha sua figura cõ seu sõ formalmente distincto da figura, \& sõ das outras; de maneyra que já mays o a, se torna i, nẽ o i, u, nẽ a, emquanto á figura, nẽ emquanto ao sõ, cõ tudo uma vogal tira \& impede a figura, \& o sõ da outra vogal ẽ nosso vulgar[...] (BARRETO, 1671, p. 212).

Segundo Barreto, o diacrítico "denota a vogal, que se tira do fím da dicçã, quando se encontra cõ outra" $(1671$, p. 212). A representação que o autor faz do sinal corresponde ao utilizado atualmente: "cuja figura he uma virgula ás avessas, nesta forma, \& he muyto frequente cõ a proposição de, quando se lhe segue vogal" (1671, p. 212). A utilização do apóstrofo se dará quando duas palavras se unem pela última vogal da palavra antecedente.

Com o título "Do til", o pároco reserva o capítulo quarenta e quatro ao diacrítico e define-o da seguinte forma: "nã he letra senã uma risquinha, ou linha; como se as letras foram mays que linhas, \& riscas, segũdo no principio dicemos" (BARRETO, 1671, p. 178).

A função do til é a supressão das letras e redução das palavras, além de substituir o uso do $<\mathrm{m}>$ e do $<\mathrm{n}>$, pois "a necessidade que do til temos, he nas dições, que acabamos per am, em, im, om, um porque quando nessas vogaes soa o acento, deyxaremos o $\mathrm{m}$ fora, \& poremos o til, ẽcima dessa tal vogal, como ẽ razã, vintẽ, jasmĩ” (BARRETO, 1671, p. 179).

Centralizamos nossa análise na função dos diacríticos, mas Barreto, diferentemente dos demais ortógrafos de sua época, é o autor que realiza referências claras aos autores em que se baseia. Suas abordagens fazem jus às leituras que realizou, aos preceitos defendidos e a uma tendência de escrever como se lê, de acordo com o princípio quintiliano (escrever como se fala) por ele defendido. (GONÇALVES, 2003, p. 874).

\section{Algumas conclusões sobre as ortografias analisadas}

A primeira menção aos diacríticos como forma de diferenciação na escrita partiu de Gândavo (1574), que, embora não os nomeie, apresenta-os sobre o grafema $<\mathrm{a}>$. Leão (1576), assim como Gândavo, procura sistematizar o uso, apresentando as formas de uso, por regras e especificações pré-determinadas.

Leão, conforme Buescu (1984, p. 154), apresenta a sua Orthographia nas seguintes partes: regras particulares para cada letra, estudo de algumas modificações, dos diphtongos, regras gerais da ortografia, os artigos, os acentos e o seu uso como sinal do tom, lista de correções e tratado dos pontos.

A novidade é a apresentação de um capítulo direcionado aos acentos, em que descreverá as formas de utilização dos diacríticos. O capítulo "Dos acentos, e qvando os deuemos usar na escriptura" relaciona a relação da diferença entre as dições e a sua representação com uso dos diacríticos agudo, grave e circunflexo. 
Até então, Fernão de Oliveira (1536) havia abordado os tons da dição, Barros (1540) faz relação entre a qualidade vocálica e sua representação na forma de diacríticos e apenas Gândavo (1574) havia reservado um capítulo para o uso dos diacríticos como sinais de diferenciação.

É notório que as anotações de Fernão de Oliveira (1536) são representadas na obra de Barros, principalmente, no que tange à abordagem fonético-fonológica. Bueno (1955, p. 243) afirma que a obra do historiador foi um plágio à gramática de Oliveira, tendo em vista que o segundo havia sido professor dos filhos do primeiro e, além disso, a abordagem de Oliveira acerca das ortografias é semelhante à abordagem de Barros. As obras de Gândavo (1574) e Leão (1576) já dimensionam capítulos específicos, que explicitam o uso dos diacríticos, diferentemente dos antecessores. Acreditamos que isso se deve à necessidade de fazer das ortografias objetos de esclarecimento e disseminação da língua portuguesa. Apesar da busca pela identidade nacional, o entrelaçamento do português e o latim são características presentes em todas as ortografias, embora utilizem diferentes discursos como valorização do idioma pátrio.

E por tais ocorrências é que identificamos, nessas ortografias, muitas similaridades com as obras linguísticas do século XVI, principalmente, Nunes do Leão (1576), muito citado por Barreto e referenciado por Vera, que, apesar de não citar explicitamente o autor, apropria-se de muitos conceitos adotados por ele em sua Ortografia. Monteiro (1992) traça-nos um panorama comparando as ortografias de Vera (1631) e Leão (1576), apresentando as semelhanças entre as duas obras.

Como explanado por Barreto (1671, p. 201), no início do capítulo que dedicou aos acentos, o uso dos diacríticos é "das mays dificeys da ortografia, como sentem todos os que dela escrevem. \& assi poucos a tẽ acertado: màs he tã importante, que uma das principaes causas, porque a pronunciaçã da lingua se faça eterna”.

A tentativa de estabelecer parâmetros para o uso, definindo como, quando e porquê utilizar os diacríticos é perceptível nas obras. Também não há um consenso sobre quais dos sinais utilizar, tendo em vista que ora apresentam a mesma função, ora representam diferentes atribuições.

Exemplos retirados do corpus, documentos produzidos nos séculos XVII e XVIII apresentam diacríticos diferentes utilizados para a mesma função: a nasalidade. Embora os ortógrafos seiscentistas apresentem, cada um a seu modo, uma sistematização dos usos, a prática dava-se de outra maneira. $\mathrm{O}$ escrivão responsável pela elaboração do documento 01 aplicou o agudo para expressar a contração da nasal $<$ m $>$ em $<$ huá $>$ e também utilizou o circunflexo para essa finalidade em $<$ huâ $>$ no mesmo documento. Localizamos o agudo com função tônica nos verbos do futuro do presente como < dirá $>$ e em $<$ hordinário $>$. O grave, embora citado por todos os autores, não foi encontrado na escrita deste documento e dos demais, que perfazem os séculos XVIII e XIX.

Se realizarmos uma comparação ao título do capítulo reservado para os diacríticos, perceberemos similaridade entre os três autores - Gândavo (1571), Leão (1576), Vera (1631) e Barreto (1671) - que introduziram o assunto, respectivamente, da seguinte forma:

(01) Dos accentos qve se hão de vsar em algũas letras, ou vocabulos que tenerem duuidosa a significação 
(02) Dos accentos, e qvando os deuemos vsar na scriptura;

(03) Dos acentos, \& viraccentos, que usão os Gregos, \& Latinos. \& quando os devemos usar na escritura;

(04) Cap. LII. Dos Acentos, como, e quando se devem usar.

O conceito de acento foi inicialmente abordado por Oliveira (1536), que não se relaciona ao uso dos diacríticos. Bluteau (1712), no Vocabulário Portuguez e Latino, apresenta significado similar ao do gramático quinhentista, mas será a partir da Orthographia (1576) de Leão que o termo passa a ser relacionado com o uso do sinal gráfico.

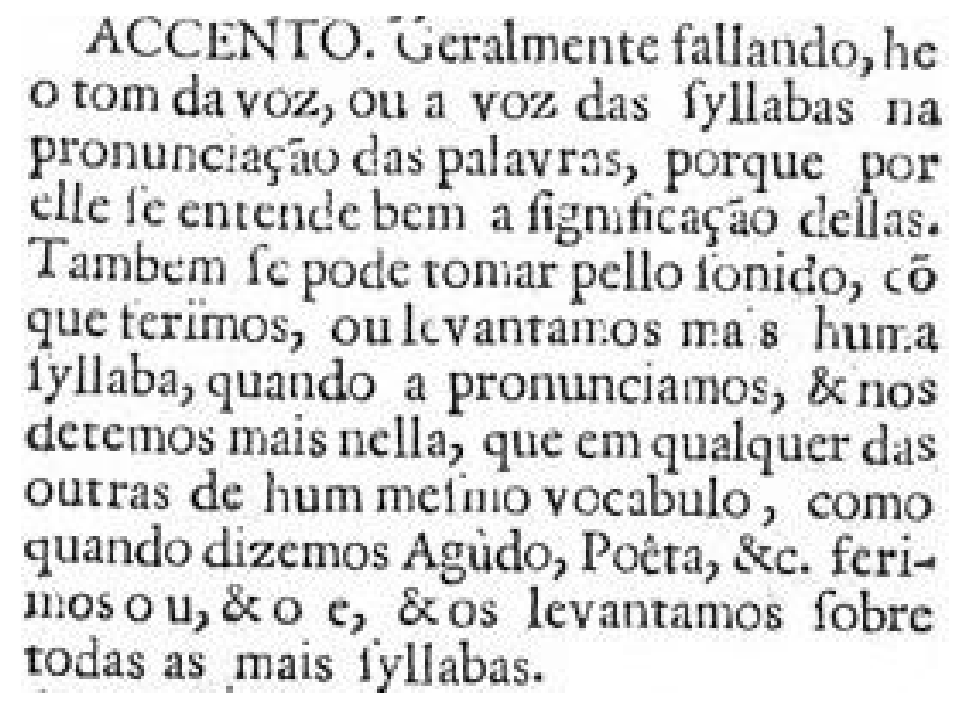

Figura 1. Definição de acento em Bluteau

O significado apresentado no Vocabulário valida o entendimento acerca do termo acento e ratifica que o uso do diacrítico para representar "o tom da voz" é parte do uso proposto pelo ortógrafo.

Barreto (1671) divide a função dos diacríticos de acordo com a função morfológica e do grau da tonicidade e abertura apresentada nas sílabas das palavras para uso do agudo e do circunflexo. Na exemplificação apresentada, fica implícito que a aplicação do agudo está atrelada à tonicidade das sílabas e altura vocálica. Ao diferenciar o diacrítico em fóra (verbo) e fôra (advérbio) faz relação entre a diferenciação de palavras homógrafas.

Vera (1631) realiza clara diferenciação entre a aplicação do agudo e do circunflexo, reservando ao primeiro o uso em sílabas tônicas fechadas e o segundo em tônicas abertas, ou seja, sua proposta de uso versa sobre a diferenciação lexical, uma vez que, conforme os exemplos apresentados, os diacríticos são utilizados para diferenciar os tempos verbais pretérito e futuro. Além disso, o circunflexo é aplicado nas sílabas pré-nasais como em Amârão, lerão, ouvîrao. 
Os Latinos usavão de três, a saber: Agudo, grave, \& circunflexo, que he composto de ambos. Do primeiro, \& do terceiro usamos os Portuguêses nas syllabas que pronunciadas altas em dicções, que tem as mesmas letras e differenção na significação de aquellas, que teem a pronunciação baixa: como amára, leéra, ouvíra, amarâ, leerâ, ouvirâ pretérito, ou futuro. [...] Assi que onde o acento faz mudança de significação, o notaremos sempre; como nas terceiras pessoas do pretérito perfeito de modo demonstrativo de todas as conjugações: porque concorrem com as terceiras pessoas do futuro do mesmo modo, \& numero as mesmas syllabas: senão que diferem no accento. Pelo que para tirarmos a diferença dos modos \& tempos, de que falamos, quando for pretérito, diremos: Amârão, lerão, ouvîrao. E quando for futuro diremos: Amaraõ, leeraõ, ouviraõ sem nenhum accento, porque se entende fazelo na ultima. (VERA, 1631, p. 42).

Reafirma a necessidade de utilização dos diacríticos para diferenciação lexical ao sugerir o uso do agudo e do circunflexo para diferenciar o nome e o verbo quando representados com a mesma escrita. Nos exemplos citados pelo autor, os verbos seriam representados com o circunflexo:

O mesmo usaremos nos nomes, onde assi for necessário, encontrando-se na significação os verbos: como jôgo, bôlo, trôco, que pronunciamos com tom baixo, que significão jogar, bolar, trocar, a diferença de jogo, bolo, troco, que são nomes, que se escrevem com acento agudo, ou sem elle. (VERA, 1631, p. 42).

Diante disso, verifica-se que Vera faz uso do agudo e do circunflexo para representar diferentes palavras com escrita idêntica ou ainda para delimitar a tonicidade silábica.

Barreto, embora reconheça a existência dos três diacríticos, assim como Vera, utiliza-se do agudo para identificar a diferença entre os tempos verbais

Se as palavras forem diversas, \& se escreverem cõ as mesmas letras, como se ve na primeyra \& terceyra pessoa do pretérito plusquam perfeyto, \& na terceyra pessoa do futuro dos verbos amar, ouvir \& c, para mostrarmos essa diversidade, escreveremos as pessoas do pretérito cõ acento agudo na penúltima, como amára, ouvíra, \& a pessoa do futuro cõo mesmo acento é a ultima, como amará ouvirá. (BARRETO, 1671, p. 205).

Ao contrário de Vera, restringe o uso do circunflexo aos verbos dissílabos para determinar a diferença lexical

[...] màs se a palavra fôr de duas silabas somente, como lêra, fora, se escreverá cõ acento circunflexo, \& se conhecerá bẽ esta diferença na segunda palavra destas duas, porque fora he primeyra \& terceyra do pretérito plusquanperfeyto de verboo sou, \& fóra cõ acento agudo, ẽ o he adverbio. (BARRETO, 1671, p. 205).

Ambos mantêm a relação já estabelecida por Leão, no final do século XVI, com pequenas modificações e acréscimo de exemplos, como fez Barreto. Quanto ao uso do grave, mantêm as mesmas opiniões. 


\section{Considerações finais}

Os olhares dos autores quanto ao emprego e até mesmo à necessidade de uso dos diacríticos é difusa, embora todos mencionem que existam três acentos que serão utilizados na língua portuguesa: o agudo, o grave e o circunflexo. De toda forma, apesar das similaridades, cada um apresenta, ao seu modo, ponderações que diferem ou complementam as conclusões já elencadas por seus antecessores.

A grande novidade em relação aos primeiros compêndios é a tentativa de estabelecer um regramento para defesa do uso de um ou outro diacrítico, com base em premissas fonológicas ou conceitos morfológicos.

A partir das análises e das propostas apresentadas, os sinais diacríticos seriam utilizados para marcar a diferença da pronunciação das sílabas. A partir disso, vemos uma preocupação com a transcrição das diferenças da pronunciação para a escrita, de forma que o aprendizado e a clareza quanto à forma como se apresentava o português fossem perceptíveis ao leitor e ao ouvinte.

Diante disso, concluímos que as propostas apresentadas nas obras dialogam com os objetivos propostos para a época: a solidificação e disseminação da língua portuguesa, perpetuando-a por meio da escrita.

\section{REFERÊNCIAS}

BARRETO, J. F. Ortografia da língua portuguesa. Lisboa: Officina de Joam da Costa, 1671.

BLUTEAU, R. Vocabulário portuguez \& latino. Coimbra: Colégio das artes da Companhia de Jesus, 1712.

BUESCU, M. L. C. Historiografia da língua portuguesa, século XVI. Lisboa: Livraria Sá da Costa Editora, 1984.

BUENO, F. S. A formação histórica da língua portuguêsa. Rio de Janeiro: Livraria Acadêmica, 1955.

COUTINHO, I. L. Gramática Histórica. Rio de Janeiro: Editora ao Livro Técnico, 2005.

GÂNDAVO, P. de M. Regras que ensinam a maneiro de escrever a orthographia da lingua portuguesa: com hum dialogo que adiante se seguem em defensam da mesma língua. Lisboa, Oficina de Antonio Gonsaluez. 1574. Disponível em: $<$ http://purl.pt/index/geral/aut/PT/29941.html>. Acesso em 02 jan. 2016.

GONÇALVES, M. F. As ideias ortográficas em Portugal: de Madureira Feijó a Gonçalves Viana (1734 - 1911). Lisboa: Fundação Calouste Gulbekian, 2003.

HESPANHA, A. M. A identidade portuguesa. In: MATTOSO, J. História de Portugal. v. 4. Lisboa: Editora Estampa, 1993. p. 19-37. 
LEÃO, D. N. Orthographia da lingoa portuguesa: obra vtil \& necessaria assi pera bem screuer a lingoa Hespanhol como a Latina \& quaesquer outras que da Latina teem origem. Lisboa, 1576. Disponível em: < http://purl.pt/index/geral/aut/PT/47390.html $>$. Acesso em: 20 mar. 2010.

MOISES, M. A literatura portuguesa através de textos. São Paulo: Editora Cultrix, 1980.

MONTEIRO, J. L de. A ortografia de Alvaro Ferreira de Vera. Revista Verba, Santiago de Compostela: Universidade de Santiago de Compostela. Disponível em: $<$ http://dspace.usc.es/bitstream/10347/3180/1/pg_081-096_verba19.pdf >. Acesso em: 29 mar. 2016.

VERA, A. F. de. Orthographia ou modo para escrever certo a língua portuguesa. Lisboa: Mathias Rodriguez, 1631.

Recebido em: 28/08/2016

Aprovado em: 29/11/2016 